\title{
New Methodology for Transient Engine Rig Experiments for Efficient Parameter Tuning
}

\author{
Björn Lundberg and Jonas Sjoblom \\ Chalmers Univ. of Technology \\ Åsa Johansson \\ Johnson Matthey \\ Björn Westerberg \\ Scania AB \\ Derek Creaser \\ Chalmers Univ. of Technology
}

\begin{abstract}
When performing catalyst modeling and parameter tuning it is desirable that the experimental data contain both transient and stationary points and can be generated over a short period of time. Here a method of creating such concentration transients for a full scale engine rig system is presented. The paper describes a valuable approach for changing the composition of engine exhaust gas going to a DOC (or potentially any other device) by conditioning the exhaust gas with an additional upstream DOC and/or SCR. By controlling the urea injection and the DOC bypass a wide range of exhaust compositions, not possible by only controlling the engine, could be achieved. This will improve the possibilities for parameter estimation for the modeling of the DOC. Important features of the resulting data include fast transients in concentrations with only small variations in temperature, $\mathrm{CO}$ concentrations with $\mathrm{HC}$ concentrations close to zero, and $\mathrm{NO}$ concentrations close to zero with significant $\mathrm{NO}_{2}$ concentration.
\end{abstract}

CITATION: Lundberg, B., Sjoblom, J., Johansson, Å., Westerberg, B. et al., "New Methodology for Transient Engine Rig Experiments for Efficient Parameter Tuning," SAE Int. J. Engines 6(4):2013, doi:10.4271/2013-01-9043.

\section{INTRODUCTION}

The diesel oxidation catalyst (DOC) is a well established technology to reduce $\mathrm{CO}$ and hydrocarbon (HC) emissions from diesel engines. Strengthened emission standards have made the importance of the DOC even greater in recent years since it plays an indispensable role in enhancing the performance of diesel particulate filters (DPF) and selective catalytic reduction (SCR) by enabling $\mathrm{NO}$ oxidation to $\mathrm{NO}_{2}$ [1]. Therefore correct predictions of the DOC performance are very important for simulations of the entire aftertreatment system.

In order to perform successful parameter estimation for modeling, data properties, such as a large experimental space and decoupling of effects and variables are of utmost importance. To achieve these properties of the data laboratory scale experiments are generally used for kinetic parameter estimation [2]. In laboratory scale it is possible to use essentially any combination of exhaust gas composition and temperature which makes it possible to estimate parameters over a wide range of conditions. This can be enabled by model-based design of experiments which explores the range of experimental conditions suitable for parameter estimation [3]. It is however difficult to fully replicate the properties of engine exhaust at lab scale. The hydrocarbon (HC) composition is for example very complex which means that a retuning of the parameters usually is necessary when kinetic parameters from lab scale are applied on a full scale system. The parameter retuning from full scale engine rig experiments such as demonstrated by Wang et al. [4]], is 
limited by the exhaust compositions that are possible for the engine to produce. For example in an engine exhaust, the concentration of $\mathrm{CO}$ is closely linked to the concentration of $\mathrm{HC}$ and the concentration of $\mathrm{NO}_{2}$ is closely linked to the concentration of NO. When switching between two engine operating points it also generally takes several minutes before the properties of the emissions have stabilized. The main reason for this lag in response is the large thermal mass between the engine and the investigated catalyst which will not only affect the transient behavior of the temperature but also of the concentrations. This behavior not only makes the experiments time consuming, but it also complicates the transient modeling of the DOC since the changes in inlet properties are far from ideal step functions. These resulting, relatively slow transients in feed concentration which are also convoluted with feed temperature transients, may provide little direct information regarding the transient behavior of the catalyst, due to for example the adsorption/desorption of reacting species and changes in the pool of adsorbed intermediate species.

Kolaczkowski et al. [5] presented a method where a pollutant (e.g. CO or propane) was injected between the engine and the studied DOC to achieve transient data without changing the engine operating point. This method also offers the great benefit that the heat accumulation problem is avoided, since the engine operating point and thereby the temperature is constant, and thus very fast transients in concentrations can be achieved. Sjöblom [] further extended this concept by also having the possibility to reduce the flow (increase residence time) and control the temperature. The reaction rates are highly dependent on both exhaust composition and temperature and the possibility to change these variables independently will significantly improve the conditions for parameter estimation.

The current study presents an approach where additional catalysts are used to change the inlet concentrations to the test-object (DOC). Since the transients are induced only by switching valve positions and SCR-control, instead of variation of engine operating point, experimentation with quicker and more selective variation in inlet conditions is enabled. Inlet compositions far from what is possible with only an engine can be achieved which will aid the estimation of parameters. In the current study the experimental setup is described and a few illustrative examples are given to describe the typical results from this concept.

\section{EXPERIMENTAL SECTION}

To achieve more controlled and faster changes in the inlet emission concentrations to the catalyst an extra DOC with the possibility for bypass flow and an SCR with urea injection were mounted before the catalyst, as illustrated in figure 1.

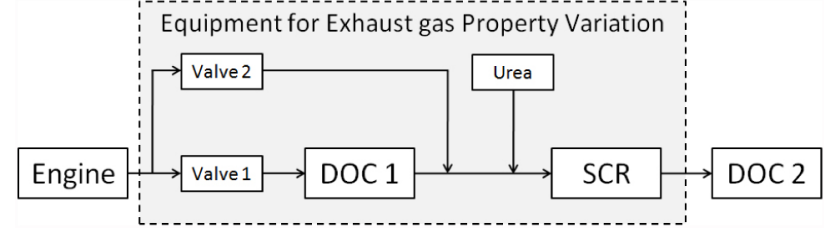

Figure 1. Experimental set-up. “DOC 2" is the testobject to be studied

The fraction of exhaust gas flow through DOC 1 allowed variation in the conversion of $\mathrm{HC}$ and $\mathrm{CO}$ to $\mathrm{CO}_{2}$ and $\mathrm{H}_{2} \mathrm{O}$, and the conversion of $\mathrm{NO}$ to $\mathrm{NO}_{2}$. By injecting different amounts of urea the conversion of $\mathrm{NO}_{2}$ and $\mathrm{NO}$ to $\mathrm{N}_{2}$ was controlled and the ratio of $\mathrm{NO}_{2}$ to $\mathrm{NO}_{\mathrm{x}}$ could be adjusted. The engine was also tuned to run with late fuel injection to achieve high $\mathrm{HC}$ and $\mathrm{CO}$ concentrations. A Vanadium-based commercial full-size SCR and a commercial platinum-only full-size DOC was used for exhaust gas property variation.

A Scania heavy duty diesel engine was used as the exhaust source and Swedish MK1 diesel, a commercial lowsulfur (approximately 5 ppm S) diesel, was used as fuel. The engine was equipped with a dynamometer control system enabling independent control of load and speed.

The experimental set-up was used for three different types of experiments that will be described in detail below. All experiments were run at more than 20 different engine operating points which resulted in a wide range of transient inlet conditions to the test-objects (DOC 2 in figure 1). Parameter tuning on the test-objects, which consisted of several different catalyst configurations, will be performed in a future study. To highlight the comparison between the experiment types the results for only one single operating point will be reported here. The operating point selected was at medium exhaust temperature (ca $300{ }^{\circ} \mathrm{C}$ ), high flow rate (ca $0.3 \mathrm{~kg} / \mathrm{s}$ ) and medium concentrations of $\mathrm{NO}, \mathrm{NO}_{2}, \mathrm{CO}$ and $\mathrm{HC}$. It should be noted that the $\mathrm{N}_{2} \mathrm{O}$ levels measured from the SCR were below 2 ppm for the presented data and will therefore not be included in the figures.

\section{RESULTS AND DISCUSSION}

Three different types of experiments were run with the set-up introduced in figure 1 . These will be referred to as type 1, 2 and, 3 experiments and will be thoroughly described in the following sections. The experiments types differ in the manner in which the transients are generated. In experiment type 1 the transients were created by changing the by-pass valve position, in experiment type 2 by changing the urea injection, and in type 3 by changing the by-pass valve position as well as the urea injection.

In the presentation of the results the thermodynamic equilibrium for the NO oxidation reaction will be frequently used as a reference (noted as "NO at eq." and " $\mathrm{NO}_{2}$ at eq." in the figures). These limits are calculated from the inlet concentrations of $\mathrm{NO}, \mathrm{NO}_{2}$, and $\mathrm{O}_{2}$ and the inlet temperature 
to the test-object. The purpose is mainly to show the limits for the conversion of $\mathrm{NO}$ to $\mathrm{NO}_{2}$ in the $\mathrm{DOC}$, but also to show how the $\mathrm{NO}_{\mathrm{x}}$ reduction in the SCR affects these limits.

\section{Type 1 Experiments - DOC Bypassing with No SCR}

In this first experimental set-up the urea injection and SCR were eliminated from the configuration shown in figure 1 to create a system with simpler dynamic behavior closer to ideal steps and where a high inlet concentration of $\mathrm{HC}$ to DOC 2 was possible. By switching valve 1 position between $20 \%$ and $90 \%$ open at the same time as valve 2 was switching between $80 \%$ and $10 \%$ open, fast transients in inlet concentrations to DOC 2 of $\mathrm{CO}, \mathrm{HC}$ and $\mathrm{NO}_{\mathrm{x}}$ were achieved (see figure 2). The difference in maximum and minimum valve positions for valve 1 and 2 were selected to compensate for differences in flow resistance between the two pathways. The selected positions resulted in about the same maximum and minimum flows through both pathways. Figure 2 also shows small variations in temperature between $302^{\circ} \mathrm{C}$ and $304^{\circ} \mathrm{C}$ which mainly originate from a difference in heat loss between the bypass pipe and DOC 1 .

The graphs of NO oxidation thermodynamic equilibrium in figure 2 show how DOC 1 pushed the concentrations of $\mathrm{NO}$ and $\mathrm{NO}_{2}$ closer to what is thermodynamically possible for the NO oxidation reaction. The figure also shows that the concentration of $\mathrm{NO}_{2}$ could exceed the $\mathrm{NO}$ concentration for an extended period of time at these conditions and that the concentrations reached stable values in a few seconds. Neither of these properties would be achievable by only changing the engine load point.

\section{Type 2 Experiments - Fixed DOC Bypassing with Urea SCR}

In this type of experiment the set-up was according to figure 1 and the purpose was mainly to widen the possible $\mathrm{NO}_{2} / \mathrm{NO}_{\mathrm{x}}$ relation and NOx dynamics compared to experiments of type 1 . The valve positions were locked at specific positions and urea was injected in pulses of 20 seconds. Five different combinations of flow through bypass and DOC 1 were used for the selected engine operating point according to table 1 . In table 1 , configuration 1 gives highest $\mathrm{NO}_{2} / \mathrm{NO}_{\mathrm{x}}$ ratio to the $\mathrm{SCR}$ and configuration 5 gives the lowest $\mathrm{NO}_{2} / \mathrm{NO}_{\mathrm{x}}$ ratio.

Table 1. Bypass configurations for experiment type 2, valve positions in \% open

\begin{tabular}{lccccc}
\hline $\begin{array}{l}\text { Configu- } \\
\text { ration }\end{array}$ & $\mathbf{1}$ & $\mathbf{2}$ & $\mathbf{3}$ & $\mathbf{4}$ & $\mathbf{5}$ \\
\hline $\begin{array}{l}\text { Valve 1 } \\
\text { position }\end{array}$ & $100 \%$ & $67 \%$ & $50 \%$ & $33 \%$ & $0 \%$ \\
$\begin{array}{l}\text { Valve 2 } \\
\text { position }\end{array}$ & $0 \%$ & $33 \%$ & $50 \%$ & $67 \%$ & $100 \%$ \\
\hline
\end{tabular}

In figure 3 the results from an experiment of type 2 with bypass configuration 1 (see table 1) and the same engine operating point as in the previously described experiment are shown. The reason for selecting configuration 1 here is that this leads to the $\mathrm{NO}_{2} / \mathrm{NO}_{\mathrm{x}}$ ratio in the SCR inlet closest to the optimal ratio of 0.5 and thus the highest $\mathrm{NO}_{\mathrm{x}}$ reduction in the SCR. Note that this is not necessarily the case for other engine operating points.

For the selected valve position configuration and engine operating point virtually all $\mathrm{HC}$ and $\mathrm{CO}$ were reduced in DOC 1 and since no valve positions were changed during the experiment the experimental data is sufficiently described with only the two panels in figure 3 .

Two cycles with successively increasing urea dosage $(0 \%$, $30 \%, 60 \%$ and $90 \%$ of stoichiometric $\mathrm{NO}_{\mathrm{x}}$ reduction) were performed, where the measured urea dosage can be seen in figure 3. The figure also shows some important features of the experiment type where the most noticeable one is that the $\mathrm{NO}_{2}$ concentration was higher than the $\mathrm{NO}$ concentration throughout the experiment. The reason is, of course, that all flow was through DOC 1 for this configuration (1) where NO was oxidized to $\mathrm{NO}_{2}$. In other words, the different configurations in table 1 had a large influence on both the $\mathrm{NO}_{2} / \mathrm{NO}_{\mathrm{x}}$ ratio, and the $\mathrm{CO}$ and $\mathrm{HC}$ concentrations in the SCR inlet and the results in figure 3 represents only one of the most extreme cases.

At the highest urea injection, the rare case was achieved where the $\mathrm{NO}$ concentration was close to zero while the $\mathrm{NO}_{2}$ concentration was as high as $100 \mathrm{ppm}$. At the same time both the $\mathrm{NO}$ and $\mathrm{NO}_{2}$ concentrations were approaching values close to the thermodynamic limits for the NO oxidation reaction. Theoretically the SCR reactions make it possible to even exceed these thermodynamic limits, which was also measured in some experiments, however only very briefly. The $\mathrm{NO}_{\mathrm{x}}$ fluctuations, which can be seen in figure 3, were a result of pressure pulses applied to remove urea stored in the injection system due to imperfect mixing between urea and injected pressurized air. The urea removed with these pressure pulses reacted with $\mathrm{NO}_{\mathrm{x}}$ resulting in sharp dips in both $\mathrm{NO}$ and $\mathrm{NO}_{2}$ that could even occur when no urea was injected.

\section{Type 3 Experiments - DOC Bypassing with Urea SCR}

The third type of experiment was a combination of the first two types, intended to provide an even wider variation in composition to the test-object. The set-up was the same as for type 2 experiments but to achieve even more dynamic concentration changes the valve positions were no longer locked; instead they were changing every $20 \mathrm{~s}$ in the same way as in type 1 experiments. With the purpose of making the data even more information rich urea was injected, for at least $20 \mathrm{~s}$, with a $10 \mathrm{~s}$ delay relative to the changes in valve position. The position of the valve 1 relative to the urea 
injection set-point is shown in panel b) of figure 4. The results from one experiment of type 3 , at the same engine operating point as experiment type 1 and 2 previously shown in figures 2 and $\underline{3}$, are shown in figure 4 .

Figure 4 shows that the $\mathrm{CO}$ and $\mathrm{HC}$ concentrations were unaffected by the variations in urea dosage. This is expected since the formed ammonia will mainly react as a $\mathrm{NO}_{\mathrm{x}}$ reductant and take part in undesired side reactions involving oxygen [7]. When figure 4 is compared to figure 2 it is also evident that the SCR catalyst itself reduced the concentration of $\mathrm{HC}$ considerably but had only a small influence on the $\mathrm{CO}$ concentration, which was slightly increased. At engine operating points with higher temperatures than the one used in figure 4, all the $\mathrm{HC}$ was consumed in this manner which gave high $\mathrm{CO}$ concentrations in the inlet to DOC 2 but no HC. This is difficult to achieve in exhaust from a standard engine rig where only the engine operating point can be changed since $\mathrm{HC}$ and $\mathrm{CO}$ concentrations generally are strongly coupled. Figure 4 also shows the urea dosage setpoint corresponding to $0 \%, 30 \%, 60 \%$ and $90 \%$ of the stoichiometric $\mathrm{NO}_{\mathrm{x}}$ reduction.

Figure 4 shows that the temperature fluctuations were small for this experiment, although a small increase of up to $4^{\circ} \mathrm{C}$ can be seen between 300 and 500 seconds where the $\mathrm{NO}_{\mathrm{x}}$ was reduced continuously for a longer period of time. The NO concentration was influenced strongly by both the urea dosage and the flow through the DOC 1.

Table 2. Description of the inlet conditions resulting from the changes in urea dosage and bypass of DOC 1 during the 40 seconds cycles in the first part of the experiment type 3.

\begin{tabular}{|c|c|c|c|c|}
\hline $\begin{array}{l}\text { Inlet } \\
\text { condi- } \\
\text { tions }\end{array}$ & $\begin{array}{c}\text { Urea } \\
\text { dosage }\end{array}$ & $\begin{array}{l}\text { Valve } 1 \\
\text { position }\end{array}$ & $\begin{array}{c}\text { Valve } 2 \\
\text { position }\end{array}$ & Description \\
\hline 1 & Off & $90 \%$ & $10 \%$ & $\begin{array}{l}\mathrm{NO}_{2} / \mathrm{NO}_{\mathrm{x}} \approx 0.5 \text { since } \\
\text { main flow through } \\
\text { DOC } 1\end{array}$ \\
\hline 2 & Off & $20 \%$ & $80 \%$ & $\begin{array}{l}\text { Low } \mathrm{NO}_{2} \text { since main } \\
\text { flow through by-pass, } \\
\text { high } \mathrm{NO} \text { since no urea } \\
\text { injected }\end{array}$ \\
\hline 3 & On & $20 \%$ & $80 \%$ & $\begin{array}{l}\mathrm{NO} \text { only consumed } \\
\text { via standard } \mathrm{SCR} \\
\text { reaction [8] since } \mathrm{NO}_{2} \\
\text { concentration is low, } \\
\text { only small amount of } \\
\mathrm{NO} \text { reduced by } \\
\text { ammonia }\end{array}$ \\
\hline 4 & On & $90 \%$ & $10 \%$ & $\begin{array}{l}\text { Higher } \mathrm{NO}_{2} / \mathrm{NO}_{\mathrm{x}} \text { ratio } \\
\text { gives more reduction } \\
\text { of both } \mathrm{NO} \text { and } \mathrm{NO}_{2} \\
\text { via fast } \mathrm{SCR} \text { reaction } \\
\text { [8]. All } \mathrm{NO}_{2} \text { reduced } \\
\text { by ammonia. }\end{array}$ \\
\hline
\end{tabular}

The delay between the urea dosage and bypass of DOC 1 resulted in different inlet conditions to the test-object during 40 second cycles in the first part of the experiment (up to about $290 \mathrm{~s}$ ). The different inlet conditions during one such cycle are described in table 2 together with the urea dosage and valve positions.

In figure 5 the results of one cycle, as described in table 2 , are depicted for measurement data between 134 and $184 \mathrm{~s}$ (from figure 4). Condition 1 can be identified at 134-148 s, condition 2 at $148-155 \mathrm{~s}$, condition 3 at $155-168 \mathrm{~s}$ and condition 4 at 168- $176 \mathrm{~s}$. The transition from one condition to another is, however, not clear cut, which mainly is a result of the deviation between urea set-point and urea dosage. As an example, inlet condition 3 where urea dosage is on and the position of valve 1 is $20 \%$ open only lasted for about 5 seconds (161 s to $166 \mathrm{~s})$. The real inlet conditions to the testobject will in other words be in transition between the inlet conditions described in table 2 for the majority of the cycle time.

If the $\mathrm{NO}_{2}$ concentration for the first $300 \mathrm{~s}$ of the experiment (figure 4) is studied it can be noted that the first two peaks (starting at around $40 \mathrm{~s}$ and at around $80 \mathrm{~s}$ ) broke through even when the urea injection was still at its highest value. The reason for the $100 \% \mathrm{NO}_{2}$ reduction before the peak broke through must therefore be that ammonia injected at an earlier time point where the $\mathrm{NO}_{2} / \mathrm{NO}_{\mathrm{x}}$ ratio was low (due to a high bypass flow) was stored and therefore was available for fast SCR reaction when the $\mathrm{NO}_{2} / \mathrm{NO}_{\mathrm{X}}$ ratio was increased. When the urea dosage was increased, the $\mathrm{NO}_{2}$ broke through increasingly later after the urea injection was stopped, resulting in increasingly narrower $\mathrm{NO}_{2}$ peaks which also indicates an increased storage.

Between 300 and $580 \mathrm{~s}$ in Figure 4, it can also be seen that the highest urea dosage was enough to reduce all $\mathrm{NO}_{2}$ but for the lower dosages some $\mathrm{NO}_{2}$ reached the test-object when the main flow was through DOC 1 resulting in peaks at 310,350 and $400 \mathrm{~s}$. At about $485 \mathrm{~s}$ the concentration of $\mathrm{HC}$ briefly exceeded the concentration of $\mathrm{NO}_{\mathrm{x}}$. Again, this is not achievable in a standard engine rig exhaust but was made possible here when the $\mathrm{NO}_{2} / \mathrm{NO}_{\mathrm{x}}$ fraction was close to 0.5 in the SCR inlet (since the main flow was through DOC 1) at the same time as the urea injection was high. The reason that not all HC was reduced in DOC 1 and the SCR is due firstly to the moderate temperature and secondly to the high $\mathrm{HC}$ concentration in the engine exhaust as a result of the late fuel injection tuning of the engine.

\section{CONCLUSIONS}

The most apparent advantage with the demonstrated experimental set-up is the possibility to achieve fast transients in concentration with only small variations in temperature. Moreover the experimental data has also shown that the following engine rig exhaust gas features are enabled by the 
experimental set-up that would not be possible with a standard engine rig:

- High $\mathrm{CO}$ concentrations with $\mathrm{HC}$ concentrations close to zero

- $\mathrm{HC}$ concentrations exceeding $\mathrm{NO}_{\mathrm{x}}$ concentration

- NO concentrations close to zero with significant $\mathrm{NO}_{2}$ concentration

The different experiment types presented also show the possibility to generate measurement data of varying complexity with the presented set-up.

The reduced correlation between temperature and concentrations, but also between individual concentrations of reactants, significantly widens the possible experimental conditions to aid full scale catalyst modeling and parameter tuning.

\section{REFERENCES}

1. Johnson, T., "Diesel Emissions in Review," SAE Int. J. Engines 4(1): 143-157, 2011, doi: $10.4271 / 2011-01-0304$

2. Voltz, Sterling E., Morgan Charles R., Liederman David, and Jacob Solomon M.. "Kinetic Study of Carbon Monoxide and Propylene Oxidation on Platinum Catalysts." Product $R \& D$ 12, no. 4 (1973): 294-301.

3. Sjoblom, J., and Creaser D.. "Latent Variable Projections of Sensitivity Data for Experimental Screening and Kinetic Modeling." Computers \& Chemical Engineering 32, no. 12 (2008): 3121-29.

4. Wang, T. J., Baek S. W., and Lee J. H.. "Kinetic Parameter Estimation of a Diesel Oxidation Catalyst under Actual Vehicle Operating Conditions." Industrial \& Engineering Chemistry Research 47, no. 8 (2008): 2528-37.

5. Kolaczkowski, S., Ye S., Yap Y., Robinson K., and Lukyanov D.. "Transient Experiments on a Full-Scale DOC-Methodology and Techniques to Support Modelling." Catalysis Today 188, no. 1 (2012): 53-61.

6. Sjöblom, J. "Bridging the Gap between Lab Scale and Full Scale Catalysis Experimentation." Topics in Catalysis 56, no. 1-8 (2013): $287-92$

7. Madia, Giuseppe, Koebel Manfred, Elsener Martin, and Wokaun Alexander. "Side Reactions in the Selective Catalytic Reduction of $\mathrm{NO}_{\mathrm{x}}$ with Various $\mathrm{NO}_{2}$ Fractions." Industrial \& Engineering Chemistry Research 41, no. 16 (2002): 4008-15.

8. Nova, Isabella, Ciardelli Cristian, Tronconi Enrico, Chatterjee Daniel et al. "NH $3-\mathrm{NO} / \mathrm{NO}_{2}$ Chemistry over V-Based Catalysts and Its Role in the Mechanism of the Fast SCR Reaction." Catalysis Today 114, no. 1 (2006): 3-12.

\section{ACKNOWLEDGMENTS}

Financial support from Swedish Energy Agency is gratefully acknowledged.

\section{ABBREVIATIONS}

DOC - Diesel Oxidation Catalyst

HC - Hydrocarbons

SCR - Selective Catalytic Reduction 


\section{FIGURES 7 INCH}

a)

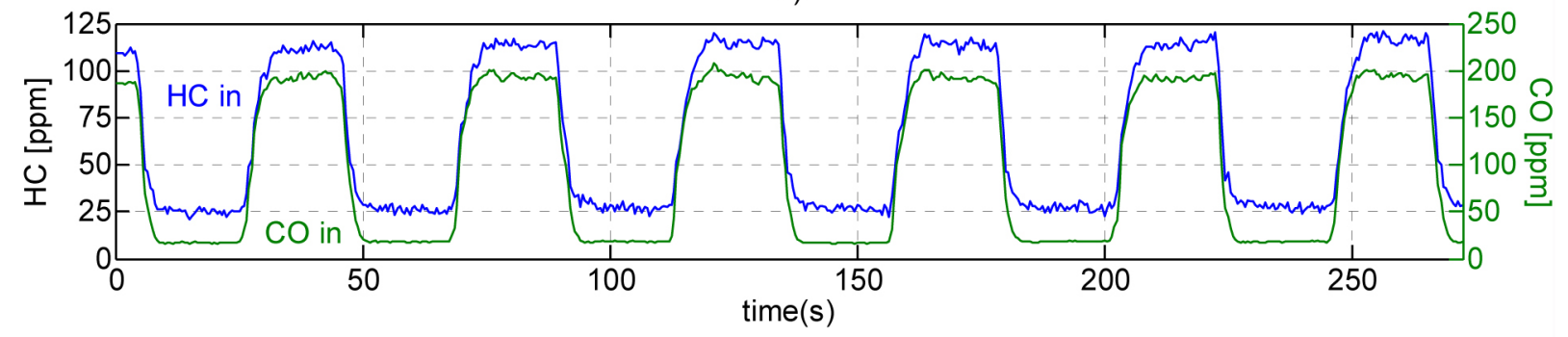

b)

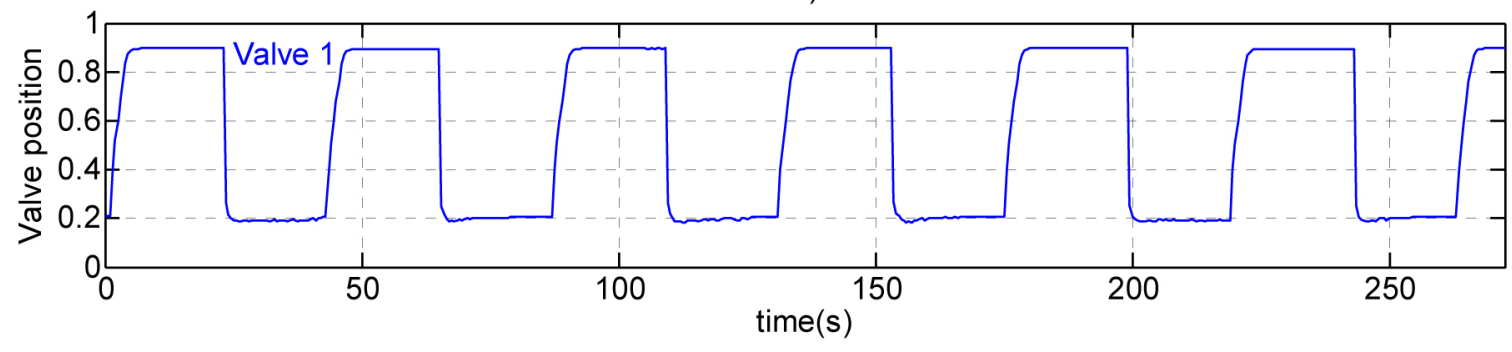

a)

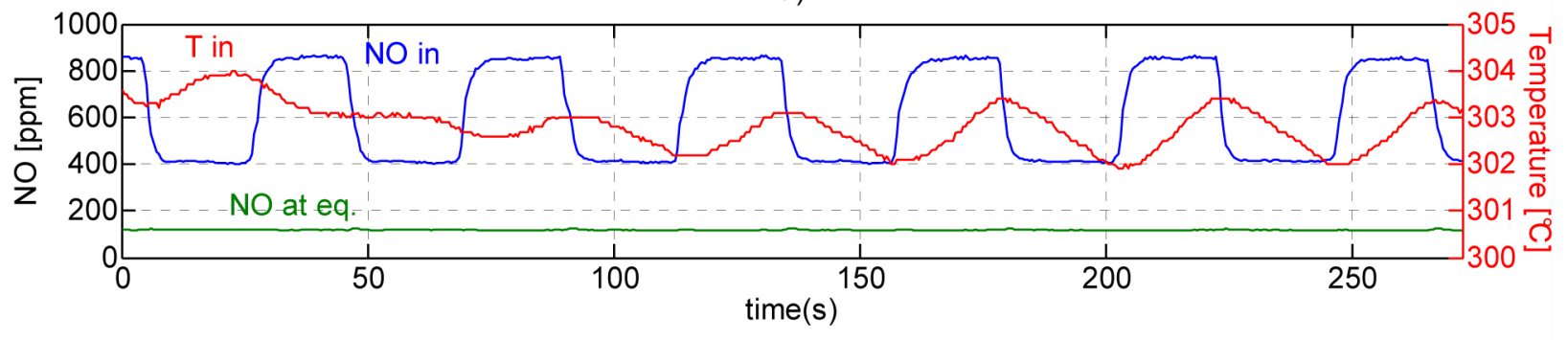

b)

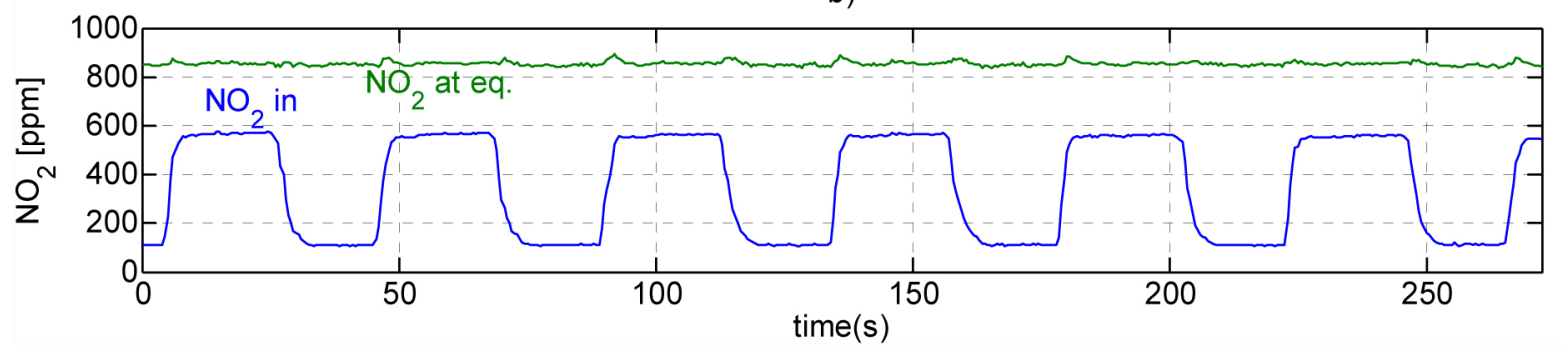

Figure 2. Data from experiment type 1. a) DOC 2 inlet mole fractions of CO and HC. b) valve position for valve 1 (see figure 1 ) where 1 is fully open and 0 is closed. c) DOC 2 inlet mole fractions and thermodynamic equilibrium for NO, and temperature. d) DOC 2 inlet mole fractions and thermodynamic equilibrium for $\mathrm{NO}_{2}$ 
a)

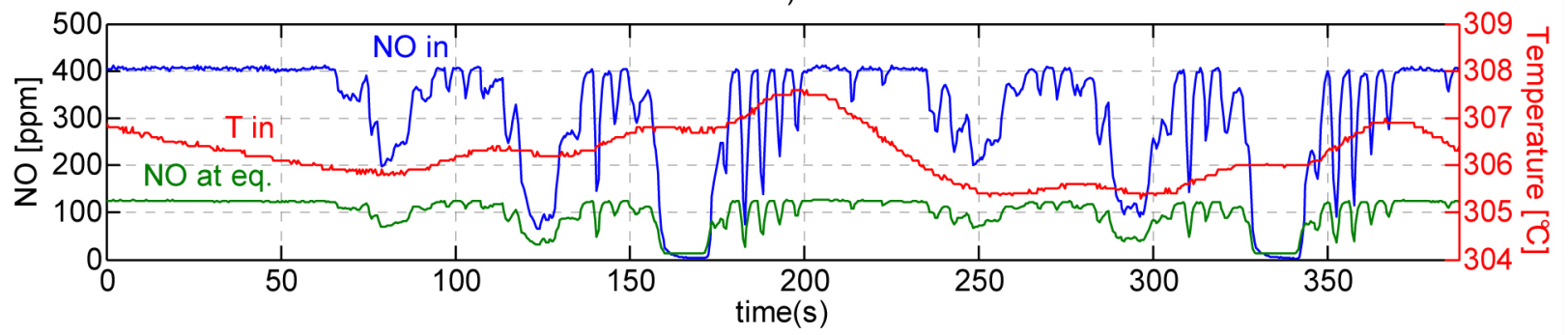

b)

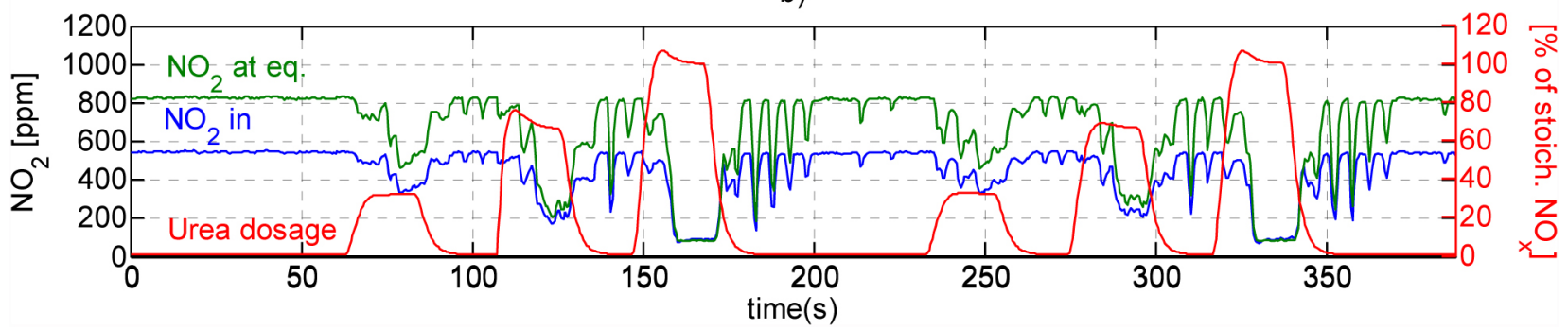

Figure 3. Data from experiment type 2. a) DOC 2 inlet mole fractions and thermodynamic equilibrium for NO, and temperature. b) DOC 2 inlet mole fractions and thermodynamic equilibrium for $\mathrm{NO}_{2}$, and urea dosage 
a)

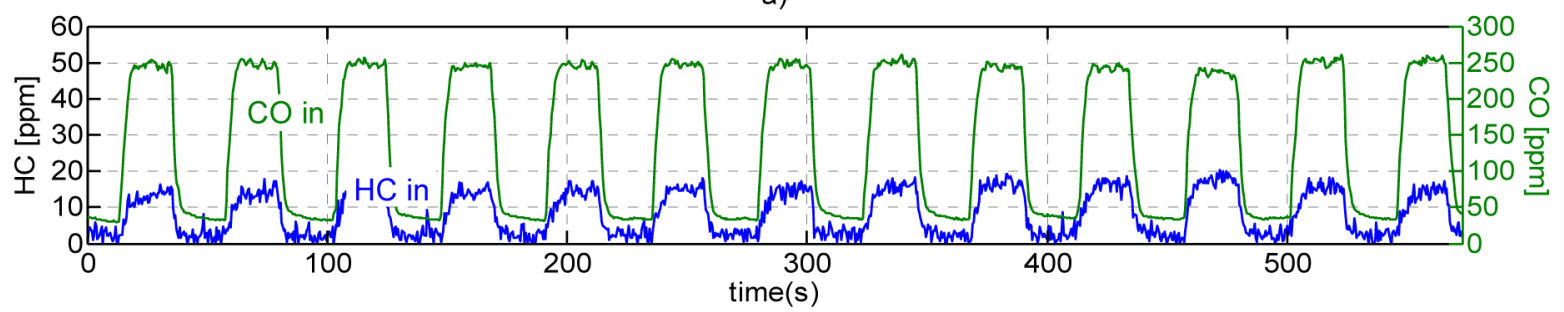

b)

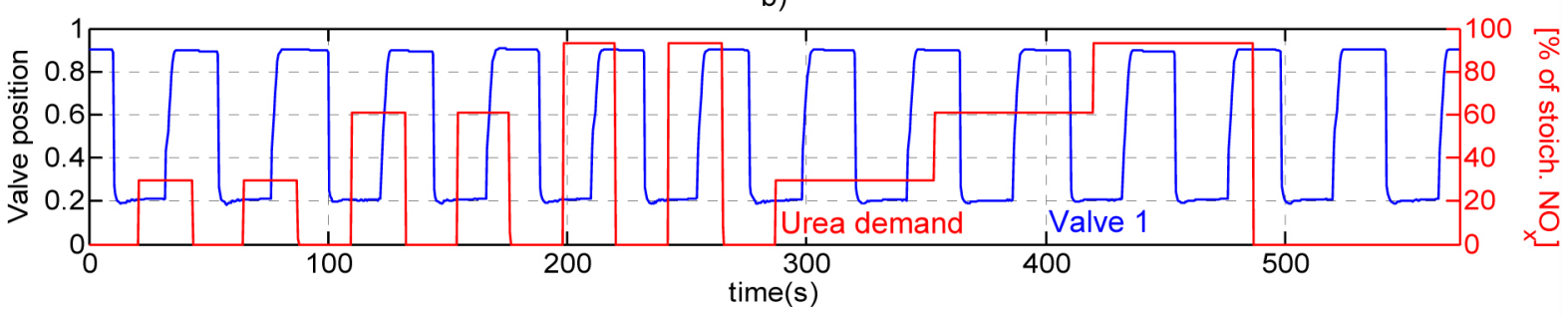

c)

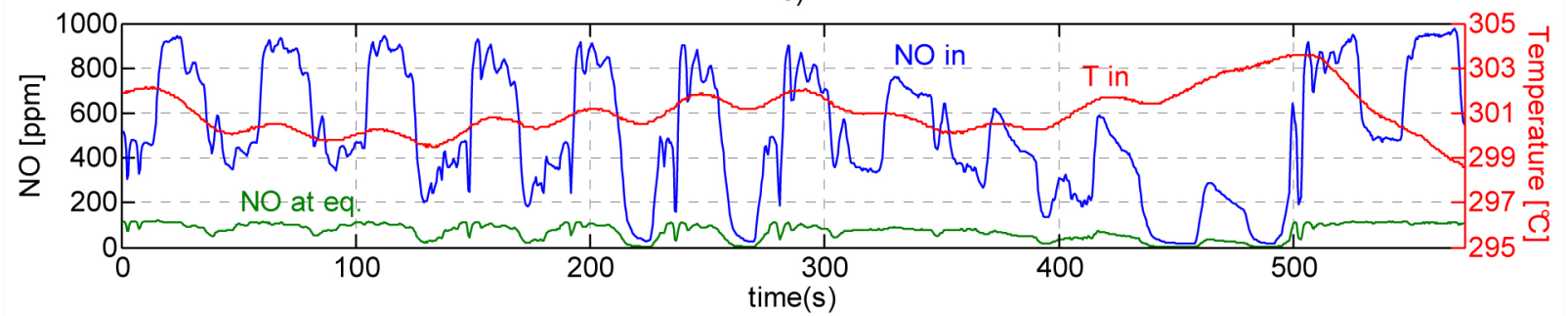

d)

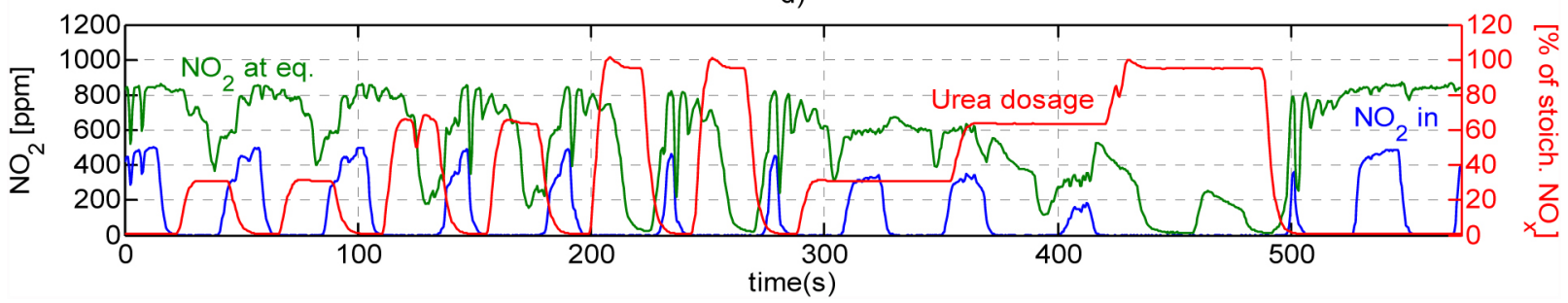

Figure 4. Data from experiment type 3. a) DOC 2 inlet mole fractions of CO and HC. b) valve position for valve 1 (see figure 1 ) where 1 is fully open and 0 is closed, and urea demand. c) DOC 2 inlet mole fractions and thermodynamic equilibrium for NO, and temperature. d) DOC 2 inlet mole fractions and thermodynamic equilibrium for $\mathrm{NO}_{2}$, and urea dosage 
a)

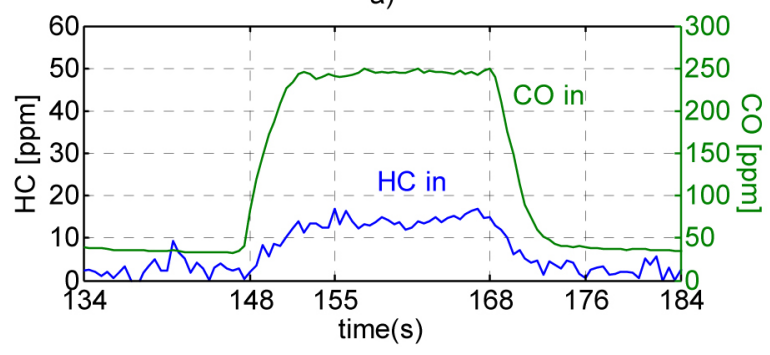

b)

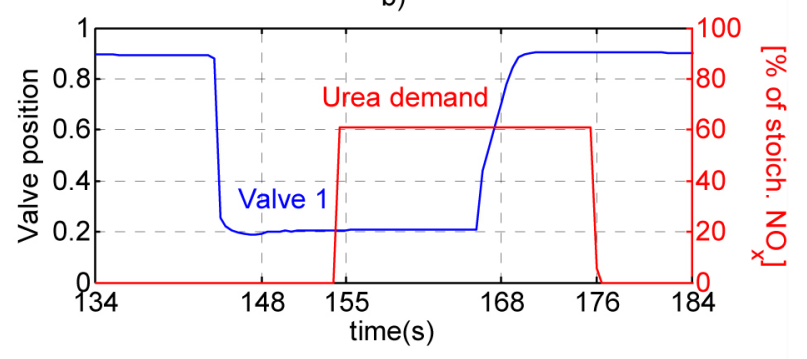

d)

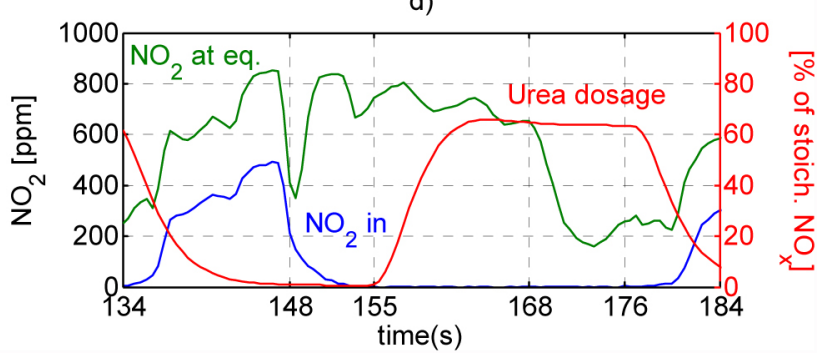

Figure 5. Magnification of the measurement data between 134 and $184 \mathrm{~s}$ from figure 4 to show the conditions described in table 2. a) DOC 2 inlet mole fractions of CO and $\mathrm{HC}$. b) valve position for valve 1 (see figure 1) where 1 is fully open and 0 is closed, and urea demand. c) DOC 2 inlet mole fractions and thermodynamic equilibrium for NO, and temperature. d) DOC 2 inlet mole fractions and thermodynamic equilibrium for $\mathrm{NO}_{2}$, and urea dosage 